\title{
The role of Coronavirus Disease (COVID-19) pandemic on anxiety and stress among the Palestinian general population: A cross sectional study
}

\section{Hamzeh Al Zabadi ( $\nabla$ halzabadi@gmail.com )}

Public Health Department, Faculty of Medicine and Health Sciences, An-Najah National University, Nablus, Palestine, PO.Box 7 https://orcid.org/0000-0002-0721-9561

Maryam Haj-Yahya

Medicine Department, Faculty of Medicine and Health Sciences, An-Najah National University, Nablus, Palestine, PO.Box 7

Noor Yaseen

Medicine Department, Faculty of Medicine and Health Sciences, An-Najah National University, Nablus, Palestine, PO.Box 7

Thair Alhroub

Medicine Department, Faculty of Medicine and Health Sciences, An-Najah National University, Nablus, Palestine, PO.Box 7

\section{Research Article}

Keywords: Anxiety, COVID-19, Lockdowns, Palestine, Quarantine, Stress.

Posted Date: October 12th, 2020

DOl: https://doi.org/10.21203/rs.3.rs-90869/v1

License: () (i) This work is licensed under a Creative Commons Attribution 4.0 International License. Read Full License 


\section{Abstract}

Background

Implication of quarantine as a global response to COVID-19 may have created a dramatic psychological and emotional effect on people, which are yet to be studied and thoroughly understood. We aimed to assess the prevalence and predictors of anxiety and stress severity among the Palestinian population.

Methods

A cross-sectional web-based survey throughout the social media on internet was conducted. An anonymous online questionnaire and snowball recruiting technique were used to target the general public in Palestine during the lockdowns of COVID-19 pandemic. Data was collected between 6- 16 April 2020 which corresponded to almost the middle interval of the strict massive lockdown measures in Palestine started 22 March to 5 May 2020. Multivariate logistic regression models were developed for the outcome variables (stress and anxiety severity).

Results

About 2819 individuals completed the questionnaire. The mean (range) age was 29.47 (18-71) years. Anxiety prevalence was $25.15 \%$, with $20.08 \%$ as mild/moderate anxiety. The prevalence of stress was $38.77 \%$ with $22.21 \%$ had mild/moderate stress. The prevalence of both anxiety and stress was $20.3 \%$ among participants. Males were less likely to have mild \moderate degree or sever $\backslash$ extremely sever degree of stress compared to females. Shortage of food supply, those having high-risk group family member, those who considered conversation with other people as source of information and those reporting higher fear of being infected were more likely to have higher degree of stress and/or anxiety compared to normal. Those with a monthly income of less than 2000 New Israeli Shekels $(<555$ USD) were significantly more likely to have mild/moderate stress compared to normal and higher monthly incomes. Gaza residency also shows significant negative predictor of stress severity compared to West Bank and Jerusalem.

\section{Conclusions}

This study reported high rates of anxiety and stress among the Palestinian general population during COVID-19 pandemic and lockdowns. These findings highlight the importance of follow up of these findings for better management of the pandemic and a preferable handling of the socio-economical factors and their impacts on the psychological health of the population.

\section{Background}

On $31^{\text {st }}$ December 2019, several cases of pneumonia with an unknown etiology were identified in Wuhan, China (1). By January $30^{\text {th }}$ 2020, the World Health Organization (WHO), declared COVID-19 outbreak in China as a Public Health Emergency of International Concern casting a threat over countries with vulnerable health systems (2). In reaction to that, quarantine has been implemented in the COVID-19 pandemic in nearly all over the world (3).

During outbreaks of infection, there would be a wide range of psychosocial impact on people (4).Similarly, to previous viral outbreaks, the ongoing COVID-19 pandemic is prompting fear, as people are likely to experience fear of getting infected or dying, feelings of helplessness, and stigma (4-6). According to previous SARS research, in the early phase of the outbreak, a range of psychiatric disturbances were reported, including persistent depression, anxiety, panic attacks, delirium, and even suicidality (7). Health professionals who worked in units and hospitals during viral outbreak also reported depression, anxiety, fear, and frustration $(6,8)$.

The implication of quarantine as a global response to COVID-19 may create a dramatic psychological and emotional effect on people (9). Mandatory contact tracing and 14 days quarantine could increase patients' anxiety and guilt about the effects of contagion, quarantine, and stigma on their families and friends (7). Those in quarantine might experience boredom, loneliness, and anger. Isolation from loved ones, the loss of freedom and the closure of schools and business, negative emotions experienced by individuals are compounded (8).

A Canadian study reports $28.9 \%$ posttraumatic stress disorder (PTSD) during SARS outbreak. According to this study, longer durations of quarantine were associated with an increased prevalence of PTSD symptoms. Acquaintance with or direct exposure to someone with a diagnosis of SARS was also associated with PTSD and depressive symptoms (9). Many of the investigations on the 
psychological impact on the non-infected community, revealed significant psychiatric morbidities which were found to be associated with younger age and increased self-blame. Those who were older, of female gender, more highly educated, with higher risk perceptions of SARS, a moderate anxiety level, a positive contact history, and those with SARS-like symptoms were more likely to take precautionary measures against the infection (6).

On $22^{\text {nd }}$ March 2020, Palestine had undergone massive quarantine for nearly 43 days (up to $5^{\text {th }}$ May 2020). However, the psychological and coping responses of the community in this quarantine and its related lockdown measures among the Palestinian population are unknown. This study aimed to assess the prevalence and predictors of anxiety and stress severity among the Palestinian population as understanding the experiences of quarantined persons is critical to maximize infectious disease containment and minimize the negative effects on those quarantined, their families, and social networks.

\section{Methods}

\section{Study population, sample and setting}

The target population comprised all people who were equal or more than 18 years old. We adopted a cross-sectional survey design to find the prevalence of stress and anxiety among the public and identify possible risk factors, during the pandemic of COVID-19 by using an anonymous online questionnaire. A snowball sampling strategy, focused on recruiting the general public living in Palestine during the pandemic was conducted. The online survey was first disseminated on Facebook to friends and they were encouraged to pass it on to others.

\section{Procedure}

As the Palestinian Government recommended the public to minimize face-to-face interaction and isolate their selves at home, potential respondents were electronically invited. They completed the questionnaires in Arabic through an online survey. Expedited ethics approval was obtained from the institutional Review Board (IRB) at An-Najah National University (Faculty of Medicine and Health Sciences). Privacy was strictly protected during the procedure. The purposes of the study and information about it were posted on the first page of the questionnaire. All respondents provided electronic informed consent before starting the questionnaire. The IRB approved our request of waiver of documentation of this method of obtaining consent. Data collection took place over 10 days (6 to 16 April 2020) which corresponds to almost the middle interval of massive quarantine in Palestine (22 March to 5 May 2020).

\section{Survey development}

Previous surveys on the assessment of mental health during quarantine in outbreaks were reviewed (10). Authors included additional questions related to the COVID-19 outbreak in Palestine. The structured questionnaire consisted of questions that covered several areas: (1) informed consent, (2) demographic data, (3) knowledge and concerns about quarantine, (4) precautionary measures against COVID-19 (5) DASS Scale form in Arabic. DASS scale is an instrument included 42-self-report items designed to measure the three related negative emotional states of depression, anxiety and tension/stress. A short version, the DASS21, is available with 7 items per scale (11). DASS scale showed an excellent Cronbach's alpha values of $0.81,0.89$ and 0.78 for the subscales of depressive, anxiety and stress respectively (12).

Arabic-language version of DASS scale was used. The form recruited from a published study over the Psychometric properties of an Arabic version of the Depression Anxiety Stress Scales (DASS), in which the results supported the universality of depression, anxiety, and stress across cultures and thus provided an initial support for the psychometric properties of the Arabic DASS (13).

A pilot study was performed on a small group of volunteers for feedback to identify ambiguities, difficult questions, record the time needed to complete the online questionnaire and therefore a very minor re-words were made to clarify some words and questions related to COVID-19 pandemic and quarantine.

\section{Statistical analysis}

DASS scale contains three subscales, each composed of seven questions. The anxiety subscale assesses autonomic arousal, skeletal muscle effects, situational anxiety, and subjective experience of anxious affect. The Stress scale assesses difficulty relaxing, nervous arousal, and being easily upset/agitated, irritable/over-reactive and impatient. Subjects were asked to use 4-point severity/frequency scales to rate the extent to which they have experienced each state over the past week. As in: 
0 - Did not apply to me at all.

1 - Applied to me to some degree, or some of the time.

2 - Applied to me to a considerable degree or a good part of time.

3 - Applied to me very much or most of the time.

Anxiety and stress scores were calculated by summing the scores for the relevant items. The scores on the DASS-21 were multiplied by 2 to calculate the final score. Scores are shown as the following (11):

Anxiety scores: Normal (0-7); Mild (8-9); moderate (10-14); severe (15-19) and extremely severe (20+). Stress scores: Normal (0-14); Mild (15-18); moderate (19-25); severe (26-33) and extremely severe (34+). DASS scores may be presented in five categorical levels.

However, in this study, and according to standardized cut-offs, we merged mild with moderate and severe with extremely severe cut-off scores to facilitate the multivariate analysis as some cells showed less than 5 cases in some categorical independent variables and this is usually accepted (14).

Data was entered into the 27th version of IBM SPSS Software (IBM SPSS Statistics for Windows, Version 27.0. Armonk, NY: IBM Corp). Descriptive analysis (median, mean and standard deviation) for continuous variables and (frequencies/percentages)for categorical independent variables were conducted. Independent t-test was used to test for significance among continuous variables and Chi-square test for categorical variables. Variables showed to be significant in bivariate analysis (with $P$-value less than 0.05 ) were included in the multinomial logistic regression models to predict the factors associated with each anxiety and stress severity degrees and presented as odds ratio and $95 \% \mathrm{Cl}$.

\section{Results}

\section{Characteristics of the study population}

In this study, 2819 individuals completed and returned the questionnaire (Table 1). The mean age of respondents was 29.47 years with SD of 10.97 years. More than two thirds $(72.6 \%)$ of respondents were females. Almost half of them $(51.4 \%)$ were single. The majority of respondents lives in West bank (83.5\%) and only $9.6 \%$ in Gaza. Around $55.1 \%(n=1552)$ of participants had an income of $2000-5000$ New Israeli Shekels (555-1388 USD) per month.

Most of participants (78.4\%) were currently study in collage or graduated recently. On the other hand, $10 \%$ of them study master or doctorate. Almost one quarter (24.6\%) were smokers and only $11.8 \%$ were health care workers. About $45.5 \%$ reported that they had high-risk group in home living with them currently.

Results showed that 1675 (59.4\%), 1558 (55.3\%) and 1536 (54.5\%) of respondents reported high levels of stay at home commitment, commitment to inside home precautions and understanding of quarantine; respectively.

\section{Quarantine characteristics of the population}

As shown in the table $2,98 \%$ of respondents believed that quarantine is important, and $2173(77.1 \%)$ expressed that they afraid of getting COVID-19 or transmitting it to others. Only $14.9 \%$ of respondents had jobs that required them to go outdoors, and only 85 (3\%) had at least one of relatives with confirmed COVID-19 disease. The two most common source of information about quarantine and precautions were social media and television or radio ( $59.5 \%$ and $18.6 \%$; respectively). Nearly, $80.2 \%$ admitted that they properly informed about quarantine. In addition, $29.3 \%$ self-reported that they do not have enough food supply to withstand quarantine period.

Quarantine duration ranged from less than 2 weeks in $6.6 \%$ to more than 4 weeks in $35.4 \%$ of the participants. Most people (38.2\%) used to spend between six to ten hours outside home before quarantine, $20.7 \%$ spent less than two hours and only $13.6 \%$ spent more than 10 hours (see table 2 for more details).

\section{Prevalence of anxiety and stress in bivariate analysis}

The prevalence of anxiety was $25.15 \%(n=709 ; 20.08 \%$ with Mild/moderate anxiety and $5.07 \%$ with severe/extremely severe). The prevalence of stress was $38.77 \%(n=1093 ; 22.21 \%$ with Mild/moderate anxiety and $16.56 \%$ with severe/extremely severe). 
In bivariate analysis, statistically significant association was found between both anxiety severity and stress severity with age (Figure 1 and 2), sex (Figure 1 and 2), social status, monthly income and the presence of high-risk group (P-value <0.05; Table 1 ). However, geographic area and educational level were found to be statistically significant with stress severity but not with anxiety.

On the other hand, the type of quarantine, having relatives or acquainted infected, and the commitment to inside home precautions were statistically significant with anxiety and not stress. Furthermore, fear of getting or transmitting COVID-19, proper information about quarantine, the source of information, and enough food supply to withstand quarantine were significant in both anxiety and stress (P-value <0.05; Table 2).

The fear of transmission had strong associations with higher levels of anxiety and stress severities $(P$-value <0.001, Table 2). People who had enough food supply to withstand quarantine period made the majority in all categories of both anxiety and stress ( $P$-value $<0.001$, Table 2). High-level commitment represented the majorities in the normal and the mild to moderate categories in the anxiety severity with $60.1 \%$ and $59.5 \%$ respectively (Table 2 ).

\section{Multinomial analysis of anxiety severity predictors}

Multinomial regression model for the variables associated with anxiety severity is shown in table 3 . As shown, anxiety severity was negatively associated with having no high-risk group family member $\{$ mild $\backslash$ moderate degree $[0 \mathrm{R}(95 \% \mathrm{Cl})=0.72(0.60-0.87)]\}$ and $\{$ sever/extremely sever $[\mathrm{OR}(95 \% \mathrm{Cl})=0.62(0.44-0.88)]$ compared to normal. People who reported not knowing any confirmed case of COVID-19 personally were significantly less likely to have higher anxiety degree compared to people who reported knowing or being in contact with confirmed cases $\{$ mild $\backslash$ moderate degree $[\mathrm{OR}(95 \% \mathrm{Cl})=0.57(0.34-0.94)]$ and $\{$ sever/extremely sever $[\mathrm{OR}(95 \% \mathrm{Cl})=0.41$ $(0.19-0.90)]\}$.

However, those who reported don't have enough food supply were more likely to have higher degree of anxiety compared to normal \{mild $\backslash$ moderate degree $[\mathrm{OR}(95 \% \mathrm{Cl})=1.52(1.23-1.88)]$ and $\{$ sever/extremely sever $[\mathrm{OR}(95 \% \mathrm{Cl})=1.88(1.30-2.74)]$.

Males were significantly less likely to have mild/moderate anxiety compared to normal [OR $(95 \% \mathrm{Cl})=0.057(0.44-0.72)]$. Those with essential jobs that required staying out home were significantly more likely to have severe/extremely severe anxiety compared to those who were asked by government to stay at home [OR $(95 \% \mathrm{Cl})=1.62(1.04-2.51)]$. Moreover, those who reported don't afraid of being infected were significantly less likely to have higher degree of anxiety severity compared to normal (see table 3).Being not properly informed about quarantine was a significant positive predictor of mild/moderate anxiety compared to normal [OR $(95 \% \mathrm{Cl})=1.35(1.06-$ 1.71)].

It should be noted that age, social status, monthly income, commitment to inside home precautions level, self-rating of commitment and source of information did not remain significant after adjusting for other variables in multinomial regression model.

\section{Multinomial analysis of stress severity predictors}

Multinomial regression model for the variables associated with stress severity is shown in table 4 . As shown, stress severity was negatively associated with age $\{$ mild $\backslash$ moderate degree $[\mathrm{OR}(95 \% \mathrm{Cl})=0.97(0.95-0.98)]\}$ and $\{$ sever/extremely sever $[\mathrm{OR}(95 \% \mathrm{Cl})=0.96$ (0.94-0.97)] compared to normal. Males were less likely to be in mild $\backslash$ moderate degree or sever $\backslash$ extremely sever degree of stress compared to females $([\mathrm{OR}(95 \% \mathrm{Cl})=0.64(0.51-0.81)]$, [OR $(95 \% \mathrm{Cl})=0.40(0.30-0.52)]$ respectively). However, those who reported shortage of food supply were more likely to have higher degree of stress compared to normal $\{$ mild $\backslash$ moderate degree $[\mathrm{OR}(95 \% \mathrm{Cl})=$ 1.49 (1.20-1.85)] and \{sever/extremely sever [OR $(95 \% \mathrm{CI})=1.96(1.54-2.49)]\}$. Respondents who reported having no high-risk group family member were less likely to have sever/extremely severe stress compared to normal [OR (95\%Cl) $=0.67(0.54-0.82)]$. On the other hand, those who reported television or radio as source of information were significantly less likely to have higher stress degree compared to people who depend on conversation with other people as source of information $\{$ mild $\backslash$ moderate degree $[\mathrm{OR}$ (95\% $\mathrm{Cl})=$ $0.56(0.32-0.95)]$ and $\{$ sever/extremely sever $[\mathrm{OR}(95 \% \mathrm{Cl})=0.52(0.29-0.92)]\}$. However, considering governmental official agencies, health care worker or social media as source of information were significantly less likely to have mild/moderate stress compared to those who considered conversation with other people as source of information.

Moreover, those who reported don't afraid of being infected were significantly less likely to have higher degree of stress severity compared to normal (see table 4).Being not properly informed about quarantine was a significant positive predictor of sever/extremely severe stress compared to normal [OR $(95 \% \mathrm{Cl})=1.39(1.07-1.80)]$. Those with a monthly income of less than 2000 New Israeli Shekels 
( $<555$ USD) were significantly more likely to have mild/moderate stress compared to normal and higher monthly incomes [OR (95\%Cl) $=1.41$ (1.03-1.91)]. Gaza residency also shows significant negative predictor of stress severity compared to West Bank and Jerusalem.

It should be noted that social status and educational level did not remain significant after adjusting for other variables in multinomial regression model.

\section{Discussion}

Anxiety and stress among the general population during COVID-19 in the Arab world were not studied before, and studies about these two important psychological consequences from all over the world are limited. In this study, the prevalence of anxiety among the Palestinian general population during COVID-19 pandemic was found to be $25.15 \%$ (20.08\% with mild/moderate anxiety and $5.07 \%$ with severe/extremely severe). The prevalence of stress among the Palestinian general population during COVID-19 pandemic was found to be $38.77 \%$ (22.21\% with mild/moderate stress and $16.56 \%$ with severe/extremely severe). However, it is worth to note that $20.3 \%$ of our population found to have both anxiety and stress, only $4.2 \%$ have sever/extremely sever degree of both anxiety and stress.

A study in West Bank and Gaza had reported that the prevalence of anxiety was $16.3 \%$, and the prevalence of acute stress was $8.3 \%$ among adults. However, this study was limited the small sample size of 627 participants, and it has been conducted 12 years ago. On the other hand, it used the Diagnostic and Statistical Manual of Mental Disorders (DSM) four criteria which was updated (15). However, due to unavailability of studies that evaluate the actual prevalence of anxiety and stress among general Palestinian population in the past years we could not compare our results to the real percentage of stress and anxiety before lockdown.

A recent study in Italy reported a prevalence of $18.7 \%$ of anxiety and $27.2 \%$ of stress among the Italian general population during COVID-19 pandemic (16). Another study in Northern Spain found that anxiety rate was $26.02 \%$ and stress rate was $33.5 \%$ among Spanish population during the same period (17). In UK, it was found that prevalence of anxiety was $21.63 \%$ during COVID- 19 pandemic (18).In china, a study found that the prevalence of anxiety was $37.4 \%$ and the prevalence of stress was $32.1 \%$ (6). Our reported stress and anxiety prevalence in the Palestinian population were near that of other population. Our study raise an alarming sign in Palestine as our population has a low number of COVID-19 cases and death at the time of the study compared to other countries with same prevalence. This could be explained by that Palestine is classified as a low middle-income country and has a low socio-economic status with special geopolitical situation which could add to the negative mental health effects during COVID-19 in Palestine (19). We did not find any study from the Arab world that evaluated anxiety or stress during COVID-19 to compare and this study could be a starting point for other future studies to cite from the Arab world.

Shortage in food supply was found to be the only factor associated with all degrees of both anxiety and stress, people who reported that food supply was inadequate during lockdown were more likely to have mild/moderate degree and sever/extremely sever degree of anxiety and stress compared to people who reported having adequate food supply. This is in accordance to a study done in Korea during 2015 MERS quarantine (20). This may be explained by that people who reported shortage of food supply were actually from low income group or they lost their jobs as a consequence to lockdown measures, as a result, they had been exposed to extreme pressure to found a new available financial source in this difficult situation to help their families to withstand quarantine.

As expected, people with low monthly income were more likely to have mild/moderate degree of stress compared to people with high monthly income, lost income and people with low monthly income were more likely to have anxiety than people with high monthly income as noted in a British study during same pandemic (18).Low household income was associated with stress according to Canadian study during SARS 2003 (9). Moreover, Korean study also reported that anxiety was more likely noted in people who reported loss to their financial source due to quarantine during MERS 2015 (20). This may be explained by the economic stress disseminated all over the countries during lockdown where low monthly income group would be the most vulnerable.

Age showed inverse relationship with stress severity during lockdown and massive quarantine in Palestine during COVID-19. This result was also noted in a Spanish study during COVID-19 pandemic (21), which also showed that age had significant negative association with anxiety degrees while in our study no association was found. In Northern Spain, it was found that 18-24 age group were the most common with anxiety and stress (17). However, a study in China found that age was not associated with anxiety or stress (6). However, an Italian study found that young age people were more likely to have anxiety (16). The young age group are the major component of the Palestinian society, most of them were university students who had during lockdown a new online teaching strategy implemented to continue the ongoing semester, these changes were not easy to cope with, as the educational system in Palestine was not prepared to an experiment like that, and this put a pressure on university students. Another explanation for relationship between age and stress

Page 6/15 
level is that young age group contains a newly graduated people who still unemployed or newly employed with no constant wage or savings to withstand quarantine.

Females were more likely to have mild/moderate degree and sever/extremely sever degree of stress compared to males. However, in a British study, it was found that males were more likely to have stress, while female were more likely to have anxiety during the same pandemic (18). In our study, females were also found to be more likely to have mild/moderate degree of anxiety. According to another study in UK during COVID-19 pandemic, gender was not associated with anxiety (22). A study in China found that females were more likely to have both anxiety and stress during the same pandemic (6). In Italy, a study found that females were more likely to have stress and anxiety compared to males (16). In the Palestinian society, females were under stress without quarantine, and quarantine only overwhelm the stress more and more. Further explanation could also be explained by that females were more likely to lose their jobs compared to males as the society prefers to employ males during stressful situations. Another explanation is that unemployed females and mothers used to be in house most of the times, and during quarantine males also have to be in home, which may increase the interaction between family members, leading to more feelings of stressful situation.

Those who don't have high risk group inside home were less likely to have mild/moderate degree of anxiety, sever/extremely severe anxiety and sever/extremely severe degree of stress. A study in UK found that people with pre-existing medical condition or living with relative with pre-existing medical condition were more likely to develop feelings like anxiety and stress (18). A higher level of anxiety and stress were more frequently reported in family with a member having pre-existing medical condition which put them at high-risk group according to Italian study (16). This could be easily explained by the fear of death of a family member if infection transmitted from outside home source by oneself or others, leading to more precautions and worrying if cases were confirmed in the city.

People who reported knowing cases confirmed with COVID-19 were more likely to have mild/moderate degree and sever/extremely severe degree anxiety. In a Korean study during quarantine for 2015 MERS pandemic, being in contact with confirmed cases of MERS was associated with higher degree of anxiety that almost equal to the degree that people with infection had (20). According to a study in Italy during COVID-19 pandemic, families with a family member with confirmed infection were more likely to have a higher degree of anxiety (16).

People who reported fear of getting COVID-19 or transmitting it were more likely to have mild/moderate degree of both anxiety and stress compared to people who did not report the same feelings. This is also noted in a study conducted in North India where they found that fear of infection and transmit infection were associated with increased level of anxiety and stress (23). Another study in Southwestern china during COVID-19 pandemic reported that anxiety was more likely noted in people who were very worried of getting infection with COVID-19 (24).

Respondents who reported having adequate information about quarantine were less likely to have mild/moderate degree of anxiety and sever/extremely severe degree of stress compared to people who concerned that they do not have enough information about quarantine. A Chinese study reported the same, according to that study, people who reported satisfaction with what they know about quarantine were less likely to report a higher degree of stress and anxiety (6). Another study in Singapore after 2003 SARS concluded that being clear with community about the infectious status will remove the uncertainty about the actual number of cases and was associated with decrease in psychological impact of outbreak (25).

People who have jobs that required going outside home were more likely to have sever/extremely severe degree of anxiety compared to people with jobs that were not allowed to go out home. A health care worker in particular was the frontline during the pandemic, according to a review of studies about the psychological impact during COVID-19, health care workers were more likely to develop anxiety due to fear of being infected or transmit the infection to household or friends (26). Another Italian study also found that people who had to work outside home were more likely to have anxiety compared to people who still can work from home (16). Usually new cases get the infection from the outside sources during working, and then they transmit it to household member.

It is worth mentioning that in our study educational level and social status had no impact on anxiety or stress severity. Whereas in another study, it was noted that people with higher educational level was more likely to have stress compared to people with low educational level (16). Another study in Southwestern China reported that marital status was significantly associated with anxiety (24). Students were more likely to have anxiety and stress (6). The difference between Palestine and the other mentioned world countries in the relationship between educational level and level of anxiety and stress may explained by that advanced educational level do not guarantee a job with high income, instead of that, some Palestinians leave collages or do not enter them and started a professional job, 
so they tend to have a good financial source earlier, making the economic difference between high and low educational level at the minimum level.

Our study could be limited by the sampling technique and therefore selection bias might be encountered mainly it was noticed that $72.8 \%$ of sample were females which might over-estimate the stress and anxiety severity and therefore our anxiety and stress rates should be interpreted with caution. Furthermore, due to social distancing during quarantine, we disseminated the survey on social media and this might in part exclude people who didn't have access to internet and social media. On the other side, this was the only possible procedure during the lockdown measures and it was useful in collecting the required information as fast and safe as possible.

This study was a cross sectional web-based survey and therefore recall and or systematic biases might have been occurred where over or under-estimation of some measures might have been occurred due to self-reporting. It should be noted however that this study has several strengths including large sample size and the sampling timeframe that corresponded to peak surge of COVID-19 cases in Palestine which had 613 cases and 5 death as per writing this paper. (27). Taking into account the worldwide nature of the risk in this pandemic, we strongly believe that these data could provide important useful information to be generalized to other countries and to future pandemics.

\section{Conclusions}

We reported high rates of anxiety and stress and different predictors of severity in the Palestinian general population during COVID-19 pandemic and lockdowns. These findings need further monitoring on the Palestinian population. Young age groups, females and those with low socio-economic status were more vulnerable to anxiety and stress. We strongly believe that this study could help generating social and health initiatives to prevent and manage the pandemic's stress and anxiety severity. This is crucial for communities to move forward and emerge from the crisis impacts. Furthermore, it is essential to provide psychological counseling and treatment during and after pandemic periods for these groups in Palestine.

\section{Declarations}

\section{Ethics approval and consent to participate}

The study aims, protocols and the informed consent forms were approved by the Institutional Review Board (IRB) at An-Najah National University.

\section{Consent for publish}

Not applicable

\section{Availability of data and materials}

Data are all contained within the article.

\section{Competing interests}

The authors declare that they have no financial and/or non-financial competing interests.

\section{Funding}

None.

\section{Authors' contributions}

$\mathrm{HA}, \mathrm{MH}, \mathrm{NY}$ and TA designed study protocol. HA coordinated the study protocol. MH, NY and TA collected the data. HA conducted the statistical analysis. HA, MH, NY and TA drafting the manuscript. All authors read and approved the final manuscript.

\section{Acknowledgements}

We are grateful to all participants in this study for the time they devoted and their understanding. 


\section{References}

1. Lu H, Stratton CW, Tang Y-W. Outbreak of pneumonia of unknown etiology in Wuhan, China: The mystery and the miracle. J Med Virol. 2020;92 (4):401-2.

2. World Health O. Novel Coronavirus (2019-nCoV): situation report, 12. Geneva: World Health Organization; 2020 2020-02-01.

3. Brooks SK, Webster RK, Smith LE, Woodland L, Wessely S, Greenberg N, et al. The psychological impact of quarantine and how to reduce it: rapid review of the evidence. The Lancet. 2020;395 (10227):912-20.

4. Hall RC, Hall RC, Chapman MJ. The 1995 Kikwit Ebola outbreak: lessons hospitals and physicians can apply to future viral epidemics. General hospital psychiatry. 2008;30 (5):446-52.

5. Rubin GJ, Potts HW, Michie S. The impact of communications about swine flu (influenza A H1N1v) on public responses to the outbreak: results from 36 national telephone surveys in the UK. Health technology assessment (Winchester, England). 2010;14 (34):183-266.

6. Wang C, Pan R, Wan X, Tan Y, Xu L, Ho CS, et al. Immediate Psychological Responses and Associated Factors during the Initial Stage of the 2019 Coronavirus Disease (COVID-19) Epidemic among the General Population in China. Int J Environ Res Public Health. 2020;17 (5):1729.

7. Xiang Y-T, Yang Y, Li W, Zhang L, Zhang Q, Cheung T, et al. Timely mental health care for the 2019 novel coronavirus outbreak is urgently needed. Lancet Psychiatry. 2020;7 (3):228-9.

8. Van Bortel T, Basnayake A, Wurie F, Jambai M, Koroma AS, Muana AT, et al. Psychosocial effects of an Ebola outbreak at individual, community and international levels. Bull World Health Organ. 2016;94 (3):210-4.

9. Hawryluck L, Gold WL, Robinson S, Pogorski S, Galea S, Styra R. SARS control and psychological effects of quarantine, Toronto, Canada. Emerg Infect Dis. 2004;10 (7):1206-12.

10. Liu S, Yang L, Zhang C, Xiang YT, Liu Z, Hu S, et al. Online mental health services in China during the COVID-19 outbreak. Lancet Psychiatry. 2020;7 (4):e17-e8.

11. Australia PFo. depression anxiety stress scales (DASS) 2018 [updated July 26, 2018. Available from: http://www2.psy.unsw.edu.au/dass//

12. Coker AO, Coker, O. O., \& Sanni, D Psychometric properties of the 21-item Depression Anxiety Stress Scale (DASS-21) African Research Review. 2018;12 (2).

13. Moussa M, Lovibond P, Laube R, Megahead H. Psychometric Properties of an Arabic Version of the Depression Anxiety Stress

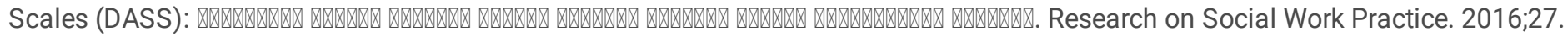

14. Allabadi H, Alkaiyat A, Alkhayyat A, Hammoudi A, Odeh H, Shtayeh J, et al. Depression and anxiety symptoms in cardiac patients: a cross-sectional hospital-based study in a Palestinian population. BMC Public Health. 2019;19 (1):232-.

15. Espié E, Gaboulaud V, Baubet T, Casas G, Mouchenik Y, Yun O, et al. Trauma-related psychological disorders among Palestinian children and adults in Gaza and West Bank, 2005-2008. Int J Ment Health Syst. 2009;3 (1):21-.

16. Mazza C, Ricci E, Biondi S, Colasanti M, Ferracuti S, Napoli C, et al. A Nationwide Survey of Psychological Distress among Italian People during the COVID-19 Pandemic: Immediate Psychological Responses and Associated Factors. Int J Environ Res Public Health. 2020;17 (9):3165.

17. Ozamiz-Etxebarria N, Dosil-Santamaria M, Picaza-Gorrochategui M, Idoiaga-Mondragon N. Niveles de estrés, ansiedad y depresión en la primera fase del brote del COVID-19 en una muestra recogida en el norte de España \%J Cadernos de Saúde Pública. 2020;36.

18. Bentall MSMMGMKHLMMMSbHKP. Anxiety, Depression, Traumatic Stress, and COVID-19 Related Anxiety in the UK General Population During the COVID-19 Pandemic. PsyArXiv 2020.

19. Group WB. World Bank Country and Lending Groups 2020 [Available from: https://datahelpdesk.worldbank.org/knowledgebase/articles/906519-world-bank-country-and-lending-groups? fbclid=IwAR3046FwMolbESTWDGpZqsi7QddKI9L_T706seFLInV8MXezte6UKeMferY.

20. Jeong H, Yim HW, Song Y-J, Ki M, Min J-A, Cho J, et al. Mental health status of people isolated due to Middle East Respiratory Syndrome. Epidemiol Health. 2016;38:e2016048-e.

21. González-Sanguino C, Ausín B, Castellanos MÁ, Saiz J, López-Gómez A, Ugidos C, et al. Mental health consequences during the initial stage of the 2020 Coronavirus pandemic (COVID-19) in Spain. Brain Behav Immun. 2020;87:172-6. 
22. Hu W, Su L, Qiao J, Zhu J, Zhou Y. Countrywide quarantine only mildly increased anxiety level during COVID-19 outbreak in China2020.

23. Upadhyay Ra, Sweta and Singh, Bhupendra and Singh, Upendra. Psychological Impact of Quarantine Period on Asymptomatic Individuals with COVID-19. SSRN. 2020.

24. Lei L, Huang X, Zhang S, Yang J, Yang L, Xu M. Comparison of Prevalence and Associated Factors of Anxiety and Depression Among People Affected by versus People Unaffected by Quarantine During the COVID-19 Epidemic in Southwestern China. Med Sci Monit. 2020;26:e924609-e.

25. Sim K, Huak Chan Y, Chong PN, Chua HC, Wen Soon S. Psychosocial and coping responses within the community health care setting towards a national outbreak of an infectious disease. J Psychosom Res. 2010;68 (2):195-202.

26. Dubey S, Biswas P, Ghosh R, Chatterjee S, Dubey MJ, Chatterjee S, et al. Psychosocial impact of COVID-19. Diabetes Metab Syndr. 2020;14 (5):779-88.

27. COVID19 Surveillance System [Internet]. Available from: http://site.moh.ps/index/covid19/?

fbclid=IwAR0qB_tYAomP6RsCn7405u2TOBOjZXMpATaPF5QYR6SI7MtmFiA14qxILBA.

\section{Tables}

\begin{tabular}{|c|c|c|c|c|c|c|c|c|c|}
\hline Variables & $\mathrm{N}(\%)$ & & nxiety sever & & $P$-value & & tress severi & & $P$-value \\
\hline & & $\begin{array}{l}\text { Normal } \\
\mathrm{n}=2110\end{array}$ & $\begin{array}{l}\text { Mild to } \\
\text { moderate } \\
\mathrm{n}=566\end{array}$ & $\begin{array}{l}\begin{array}{l}\text { Sever to } \\
\text { extremely } \\
\text { severe }\end{array} \\
\mathrm{n}=143\end{array}$ & & $\begin{array}{l}\text { Normal } \\
\mathrm{n}=1726\end{array}$ & \begin{tabular}{|l|}
$\begin{array}{l}\text { Mild to } \\
\text { moderate }\end{array}$ \\
$\mathrm{n}=626$
\end{tabular} & $\begin{array}{l}\begin{array}{l}\text { Sever to } \\
\text { extremely } \\
\text { severe }\end{array} \\
\mathrm{n}=467\end{array}$ & \\
\hline Age & $2819(100)$ & Mean $=30.06$ & Mean $=27.86$ & Mean $=27.10$ & $<0.001 *$ & Mean $=31.15$ & Mean $=27.34$ & Mean $=26.10$ & $<0.001^{*}$ \\
\hline & & $\mathrm{SD}=11.18$ & $\mathrm{SD}=10.27$ & $\mathrm{SD}=9.60$ & $\begin{array}{l}\text { (ANOVA- } \\
\text { test) }\end{array}$ & $\mathrm{SD}=11.77$ & $\mathrm{SD}=9.33$ & $\mathrm{SD}=8.38$ & $\begin{array}{l}\text { (ANOVA- } \\
\text { test) }\end{array}$ \\
\hline Sex & & & & & & & & & \\
\hline Male & \begin{tabular}{|l|}
$768(27.2)$ \\
\end{tabular} & \begin{tabular}{|l|}
$619(29.3)$ \\
\end{tabular} & 112(19.8) & $37(25.9)$ & $<0.001 *$ & $549(31.8)$ & \begin{tabular}{|l|}
$140(22.4)$ \\
\end{tabular} & $79(16.9)$ & $\begin{array}{l}<0.001^{*} \\
\end{array}$ \\
\hline Female & \begin{tabular}{|l|}
$2051(72.8)$ \\
\end{tabular} & \begin{tabular}{|l}
$1491(70.7)$ \\
\end{tabular} & $\begin{array}{l}454(80.2) \\
\end{array}$ & $106(74.1)$ & & $1177(68.2)$ & \begin{tabular}{|l|}
$486(77.6)$ \\
\end{tabular} & $388(83.1)$ & \\
\hline Social stat & & & & & & & & & \\
\hline $\begin{array}{l}\text { Single } \\
\end{array}$ & \begin{tabular}{|l|l}
$1449(51.4)$ \\
\end{tabular} & \begin{tabular}{|l|l}
$1040(49.3)$ \\
\end{tabular} & $325(57.4)$ & $84(58.7)$ & 0.001* & $822(47.6)$ & $344(55)$ & $283(60.6)$ & $\begin{array}{l}<0.001^{*} \\
\end{array}$ \\
\hline Relationship & $1370(48.6)$ & \begin{tabular}{|l|}
$1070(50.7)$ \\
\end{tabular} & $241(42.6)$ & $59(41.3)$ & & $904(52.4)$ & $282(45)$ & 184(39.4) & \\
\hline Residency & & & & & & & & & \\
\hline Village & \begin{tabular}{|l|}
$1380(49)$ \\
\end{tabular} & \begin{tabular}{|l|l}
$1047(49.6)$ \\
\end{tabular} & $275(48.6)$ & $58(40.6)$ & 0.184 & $865(50.1)$ & \begin{tabular}{|l|}
$306(48.9)$ \\
\end{tabular} & $209(44.8)$ & 0.08 \\
\hline City & \begin{tabular}{|l|}
$1292(45.8)$ \\
\end{tabular} & \begin{tabular}{|l|}
$958(45.5)$ \\
\end{tabular} & \begin{tabular}{|l}
$261(46.1)$ \\
\end{tabular} & $73(51)$ & & $780(45.2)$ & \begin{tabular}{|l|}
$289(46.2)$ \\
\end{tabular} & $223(47.8)$ & \\
\hline Camp & \begin{tabular}{|l|}
$147(5.2)$ \\
\end{tabular} & 105(5) & $30(5.3)$ & $12(8.4)$ & & $81(4.7)$ & $31(5)$ & $35(7.5)$ & \\
\hline Geographi & area & & & & & & & & \\
\hline West bank & \begin{tabular}{|l}
$2354(83.5)$ \\
\end{tabular} & \begin{tabular}{|l}
$1778(84.3)$ \\
\end{tabular} & $4465(82.2)$ & 111(77.6) & 0.066 & $1464(84.8)$ & \begin{tabular}{|l|}
$518(82.7)$ \\
\end{tabular} & $372(79.7)$ & 0.011* \\
\hline Gaza strip & \begin{tabular}{|l|}
$270(9.6)$ \\
\end{tabular} & \begin{tabular}{|l|}
$189(9)$ \\
\end{tabular} & $58(10.2)$ & $23(16.1)$ & & $149(8.6)$ & $57(9.1)$ & $64(13.7)$ & \\
\hline Jerusalem & \begin{tabular}{|l|}
$195(6.9)$ \\
\end{tabular} & \begin{tabular}{|l|}
$143(6.8)$ \\
\end{tabular} & $43(7.6)$ & $9(6.3)$ & & $113(6.5)$ & 51(8.1) & $31(6.6)$ & \\
\hline Education & 1 level & & & & & & & & \\
\hline $\begin{array}{l}\text { Secondary } \\
\text { or less }\end{array}$ & \begin{tabular}{|l}
$326(11.6)$ \\
\end{tabular} & \begin{tabular}{|l|}
$241(11.4)$ \\
\end{tabular} & $69(12.2)$ & $16(11.2)$ & 0.127 & 206(11.9) & $73(11.7)$ & $47(10.1)$ & \begin{tabular}{|l|}
$0.018^{*}$ \\
\end{tabular} \\
\hline Collage & \begin{tabular}{|l|}
$2211(78.4)$ \\
\end{tabular} & \begin{tabular}{|l|}
$1647(78.1)$ \\
\end{tabular} & \begin{tabular}{|l}
$456(80.6)$ \\
\end{tabular} & $108(75.5)$ & & $1323(76.7)$ & \begin{tabular}{|l|}
$506(80.8)$ \\
\end{tabular} & $382(81.8)$ & \\
\hline $\begin{array}{l}\text { Master or } \\
\text { doctorate }\end{array}$ & $282(10)$ & \begin{tabular}{|l|}
$222(10.5)$ \\
\end{tabular} & $41(7.2)$ & 19(13.3) & & 197(11.4) & \begin{tabular}{|l|}
$47(7.5)$ \\
\end{tabular} & $38(8.1)$ & \\
\hline Health c & worker & & & & & & & & \\
\hline Yes & \begin{tabular}{|l|}
$332(11.8)$ \\
\end{tabular} & \begin{tabular}{|l|}
$251(11.9)$ \\
\end{tabular} & $62(11)$ & $19(13.3)$ & 0.701 & 1534(88.9) & \begin{tabular}{|l|}
$555(88.7)$ \\
\end{tabular} & $398(85.2)$ & \begin{tabular}{|l|l|}
0.088 \\
\end{tabular} \\
\hline No & $2487(88.2)$ & \begin{tabular}{|c|}
$1859(88.1)$ \\
\end{tabular} & $504(89)$ & $124(86.7)$ & & 192(11.1) & \begin{tabular}{|l|}
$71(11.3)$ \\
\end{tabular} & $69(14.8)$ & \\
\hline Monthly in & come & & & & & & & & \\
\hline$<2000$ & \begin{tabular}{|l}
$568(20.1)$ \\
\end{tabular} & \begin{tabular}{|l|}
$399(18.9)$ \\
\end{tabular} & $126(22.3)$ & $43(30.1)$ & $0.011^{*}$ & $303(17.6)$ & \begin{tabular}{|l}
$145(23.2)$ \\
\end{tabular} & $120(25.7)$ & $<0.001^{*}$ \\
\hline $2000-5000$ & $1552(55.1)$ & $1177(55.8)$ & $309(54.6)$ & $66(46.1)$ & & $970(56.2)$ & \begin{tabular}{|l|}
$349(55.7)$ \\
\end{tabular} & $223(49.9)$ & \\
\hline$>5000$ & $699(24.8)$ & \begin{tabular}{|l|}
$534(25.3)$ \\
\end{tabular} & $131(23.1)$ & $34(23.8)$ & & $453(26.2)$ & 132(21.1) & $114(24.4)$ & \\
\hline Smokingls & hisha & & & & & & & & \\
\hline Yes & \begin{tabular}{|l|}
$693(24.6)$ \\
\end{tabular} & \begin{tabular}{|l}
$511(24.2)$ \\
\end{tabular} & $143(25.3)$ & $39(27.3)$ & 0.653 & $415(24)$ & \begin{tabular}{|l|}
$156(24.9)$ \\
\end{tabular} & $122(26.1)$ & 0.635 \\
\hline No & \begin{tabular}{|l}
$2126(75.4)$ \\
\end{tabular} & \begin{tabular}{|l}
$1599(75.8)$ \\
\end{tabular} & \begin{tabular}{|l|}
$423(74.7)$ \\
\end{tabular} & $104(72.7)$ & & $1311(76)$ & \begin{tabular}{|l|}
$470(75.1)$ \\
\end{tabular} & $345(73.9)$ & \\
\hline High risk & roup in ho & ne & & & & & & & \\
\hline Yes & $1283(45.5)$ & \begin{tabular}{|l|}
$911(43.2)$ \\
\end{tabular} & $292(51.6)$ & $80(55.9)$ & $<0.001^{*}$ & $747(43.3)$ & \begin{tabular}{|l|}
$291(46.5)$ \\
\end{tabular} & $245(52.5)$ & \begin{tabular}{|l|}
$0.002^{*}$ \\
\end{tabular} \\
\hline No & \begin{tabular}{|l|}
$1536(54.5)$ \\
\end{tabular} & \begin{tabular}{|l|}
$1199(56.8)$ \\
\end{tabular} & \begin{tabular}{|l|}
$274(48.4)$ \\
\end{tabular} & $63(44.1)$ & & $979(56.7)$ & \begin{tabular}{|l}
$335(53.5)$ \\
\end{tabular} & $222(47.5)$ & \\
\hline
\end{tabular}




\begin{tabular}{|c|c|c|c|c|c|c|c|c|c|}
\hline \multirow[t]{2}{*}{ Variables } & \multirow[t]{2}{*}{$\mathbf{N}(\%)$} & \multicolumn{3}{|c|}{ Anxiety severity } & \multirow[t]{2}{*}{$P$-value } & \multicolumn{3}{|c|}{ Stress severity } & \multirow[t]{2}{*}{$P$-value } \\
\hline & & $\begin{array}{l}\text { Normal } \\
\mathrm{n}=2110\end{array}$ & $\begin{array}{l}\text { Mild to } \\
\text { moderate } \\
\mathrm{n}=566\end{array}$ & 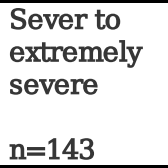 & & $\begin{array}{l}\text { Normal } \\
\mathrm{n}=1726\end{array}$ & $\begin{array}{l}\text { Mild to } \\
\text { moderate } \\
\mathrm{n}=626\end{array}$ & $\begin{array}{l}\begin{array}{l}\text { Sever to } \\
\text { extremely } \\
\text { severe }\end{array} \\
\mathrm{n}=467\end{array}$ & \\
\hline \multicolumn{10}{|c|}{ Do you think quarantine is important? } \\
\hline Yes & $2763(98)$ & $2069(98.1)$ & $553(97.7)$ & 141(98.6) & \multirow[t]{2}{*}{0.758} & 1693(98.1) & $612(97.8)$ & $458(98.1)$ & \multirow[t]{2}{*}{0.879} \\
\hline No & $56(2)$ & $41(1.9)$ & $13(2.3)$ & $2(1.4)$ & & $33(1.9)$ & $14(2.2)$ & $9(1.9)$ & \\
\hline \multicolumn{10}{|l|}{ Type of quarantine } \\
\hline $\begin{array}{l}\text { I have to work } \\
\text { outside home }\end{array}$ & $421(14.9)$ & $309(14.6)$ & $79(14)$ & $33(23.1)$ & \multirow[t]{2}{*}{$0.018^{*}$} & $269(15.6)$ & 87(13.9) & 65(13.9) & \multirow[t]{2}{*}{0.476} \\
\hline $\begin{array}{l}\text { Obliged to stay at } \\
\text { home }\end{array}$ & $2398(85.1)$ & 1801(85.4) & $487(86)$ & 110(76.9) & & 1457(84.4) & $539(86.1)$ & $402(86.1)$ & \\
\hline \multicolumn{10}{|c|}{ Any of relatives or acquainted infected? } \\
\hline Yes & $85(3)$ & $54(2.6)$ & $23(4.1)$ & $8(5.6)$ & \multirow[t]{2}{*}{$0.032^{*}$} & $44(2.5)$ & $25(4)$ & $16(3.4)$ & \multirow[t]{2}{*}{0.165} \\
\hline No & \begin{tabular}{|l|l}
$2734(97)$ \\
\end{tabular} & $2056(97.4)$ & $543(95.9)$ & $135(94.4)$ & & $1682(97.5)$ & $601(96)$ & $451(96.6)$ & \\
\hline \multicolumn{10}{|c|}{ Afraid of getting COVID-19 or transmit it? } \\
\hline Yes & $2173(77.1)$ & $1582(75)$ & $478(84.5)$ & $113(79)$ & \multirow[t]{2}{*}{$<0.001 *$} & $1284(74.4)$ & $519(82.9)$ & $370(79.2)$ & \multirow[t]{2}{*}{$<0.001 *$} \\
\hline No & \begin{tabular}{|l|l|}
$646(22.9)$ \\
\end{tabular} & $528(25)$ & \begin{tabular}{|l|}
$88(15.5)$ \\
\end{tabular} & $30(21)$ & & $442(25.6)$ & $107(82.9)$ & $97(20.8)$ & \\
\hline \multicolumn{10}{|c|}{ Properly informed about quarantine } \\
\hline Yes & $2262(80.2)$ & $1722(81.6)$ & $432(76.3)$ & $108(75.5)$ & \multirow[t]{2}{*}{$0.007 *$} & $1424(82.5)$ & $487(77.8)$ & $351(75.2)$ & \multirow[t]{2}{*}{$<0.001 *$} \\
\hline No & \begin{tabular}{|l|l|}
$557(19.8)$ \\
\end{tabular} & $388(18.4)$ & $134(23.7)$ & $35(24.5)$ & & $302(17.5)$ & $139(22.2)$ & $116(24.8)$ & \\
\hline Source of inform & tion & & & & & & & & \\
\hline Television or radio & $525(18.6)$ & $392(18.6)$ & $102(18)$ & $31(21.7)$ & & $354(20.5)$ & $101(16.1)$ & $70(15)$ & $0.001 *$ \\
\hline $\begin{array}{l}\text { Official government } \\
\text { agencies }\end{array}$ & $359(12.7)$ & $274(13)$ & $71(12.5)$ & $14(9.8)$ & & $232(13.4)$ & $66(10.5)$ & $61(13.1)$ & \\
\hline A health care worker & $159(5.6)$ & $124(5.9)$ & $21(3.7)$ & $14(9.8)$ & & $102(5.9)$ & $30(4.8)$ & $27(5.8)$ & \\
\hline Social media & \begin{tabular}{|c|}
$1676(59.5)$ \\
\end{tabular} & $1255(59.5)$ & $344(60.8)$ & $77(53.8)$ & $0.038^{*}$ & $991(57.4)$ & $401(64.1)$ & $284(60.8)$ & \\
\hline $\begin{array}{l}\text { Conversation with } \\
\text { other people }\end{array}$ & $100(3.6)$ & $65(3.1)$ & $28(4.9)$ & $7(4.9)$ & & $47(2.7)$ & $28(4.5)$ & $25(5.4)$ & \\
\hline Enough food sup] & to withs & and quarar & tine period' & & & & & & \\
\hline Yes & \begin{tabular}{|l|l|l}
$1994(70.7)$ \\
\end{tabular} & $1539(7.2 .9)$ & $371(65.5)$ & $84(58.7)$ & $<0.001 *$ & $1287(74.6)$ & $417(66.6)$ & $290(62.1)$ & $<0.001^{*}$ \\
\hline No & \begin{tabular}{|l|}
$825(29.3)$ \\
\end{tabular} & $571(27.1)$ & 195(34.5) & $59(41.3)$ & & $439(25.4)$ & $209(33.4)$ & 177(37.9) & \\
\hline Quarantine durat & & & & & & & & & \\
\hline $1-2$ weeks & $187(6.6)$ & $148(7)$ & $27(4.8)$ & $12(8.4)$ & 0.179 & $119(6.9)$ & $38(6.1)$ & $30(6.4)$ & 0.262 \\
\hline $2-3$ weeks & \begin{tabular}{|l}
$847(30.1)$ \\
\end{tabular} & $650(30.8)$ & $154(27.2)$ & $43(30.1)$ & & $541(31.3)$ & $182(29.1)$ & $124(26.6)$ & \\
\hline 3-4 weeks & \begin{tabular}{|l}
$786(27.9)$ \\
\end{tabular} & $578(27.4)$ & \begin{tabular}{|l|}
$172(30.4)$ \\
\end{tabular} & $36(25.2)$ & & $474(27.5)$ & $167(26.7)$ & $145(31)$ & \\
\hline$>4$ weeks & \begin{tabular}{|l}
$999(35.4)$ \\
\end{tabular} & $734(34.8)$ & \begin{tabular}{|l|}
$213(37.6)$ \\
\end{tabular} & $52(36.4)$ & & $592(34.3)$ & $239(38.2)$ & $168(36)$ & \\
\hline Average & home bef & re quarant & & & & & & & \\
\hline$<2$ hours & $584(20.7)$ & $430(20.4)$ & $121(21.4)$ & $33(23.1)$ & & $341(19.8)$ & $144(23)$ & \begin{tabular}{|l}
$99(21.2)$ \\
\end{tabular} & 0.200 \\
\hline 2-6 hours & \begin{tabular}{|l}
$776(27.5)$ \\
\end{tabular} & $596(28.2)$ & $140(24.7)$ & $40(28)$ & & $483(28)$ & $181(28.9)$ & $112(24)$ & \\
\hline 6-10 hours & $1075(38.2)$ & $808(38.3)$ & $221(39)$ & $46(32.2)$ & 0.399 & $672(38.9)$ & $216(34.5)$ & $187(40)$ & \\
\hline$>10$ hours & $384(13.6)$ & $276(13.1)$ & $84(14.8)$ & $24(16.8)$ & & $230(13.3)$ & $85(13.6)$ & \begin{tabular}{|l|}
$69(14.8)$ \\
\end{tabular} & \\
\hline Stay at home con & mitment & & & & & & & & \\
\hline Low level & 1144(40.6) & $946(44.8)$ & $263(46.5)$ & $74(51.7)$ & 0.242 & $792(45.9)$ & $291(46.5)$ & $200(42.8)$ & 0.428 \\
\hline High level & 1675(59.4) & $1164(55.2)$ & \begin{tabular}{|l}
$303(53.5)$ \\
\end{tabular} & $69(48.3)$ & & $934(54.1)$ & $335(53.5)$ & $267(57.2)$ & \\
\hline Commitmen & side home & recautions & & & & & & & \\
\hline Low level & 1261(44.7) & $842(39.9)$ & $229(40.5)$ & $73(51)$ & $0.032 *$ & $714(41.4)$ & $252(40.3)$ & 178(38.1) & 0.439 \\
\hline High level & \begin{tabular}{|l|}
$1558(55.3)$ \\
\end{tabular} & $1268(60.1)$ & \begin{tabular}{|l|}
$337(59.5)$ \\
\end{tabular} & $70(49) 1$ & & $1012(58.6)$ & $374(59.7)$ & $289(61.9)$ & \\
\hline Understanding of & quarantine & & & & & & & & \\
\hline Low level & $1283(45.5)$ & $946(44.8)$ & $250(44.2)$ & $65(45.5)$ & 0.946 & $774(44.8)$ & $284(45.4)$ & 203(43.5) & 0.814 \\
\hline High level & \begin{tabular}{|l}
$1536(54.5)$ \\
\end{tabular} & $1164(55.2)$ & \begin{tabular}{|l}
$316(55.8)$ \\
\end{tabular} & $78(54.5)$ & & $952(55.2)$ & $342(54.6)$ & \begin{tabular}{|l}
$264(56.5)$ \\
\end{tabular} & \\
\hline Self-rating of & 2819(100) & Mean $=8.49$ & Mean $=8.60$ & Mean $=8.15$ & $0.034^{*}$ & Mean=8.45 & Mean $=8.52$ & Mean $=8.63$ & 0.149 \\
\hline commitment & & $\mathrm{SD}=1.81$ & $\mathrm{SD}=1.88$ & $\mathrm{SD}=2.11$ & $\begin{array}{l}\text { (ANOVA- } \\
\text { test) }\end{array}$ & $\mathrm{SD}=1.84$ & $\mathrm{SD}=1.81$ & $\mathrm{SD}=1.87$ & $\begin{array}{l}\text { (ANOVA- } \\
\text { test) }\end{array}$ \\
\hline
\end{tabular}


'able 3: Multinomial regression model for the variables associated with anxiety severity" $(\mathrm{N}=2819)$.

\begin{tabular}{|c|c|c|c|c|c|c|c|c|}
\hline \multirow[b]{2}{*}{ Tariable } & \multicolumn{4}{|c|}{ Mild to moderate } & \multicolumn{4}{|c|}{ Severe to extremely severe } \\
\hline & B & SE & OR (95\%CI) & $\begin{array}{l}P \text { - } \\
\text { value }\end{array}$ & B & SE & $\begin{array}{l}\text { OR } \\
(95 \% \mathrm{CI})\end{array}$ & $\begin{array}{l}P \text { - } \\
\text { value }\end{array}$ \\
\hline ige (continuous) & -0.11 & 0.006 & $\begin{array}{l}0.99(0.98- \\
1.00) \\
\end{array}$ & 0.070 & -0.02 & 0.012 & $\begin{array}{l}0.98(0.96- \\
1.00)\end{array}$ & 0.056 \\
\hline \multicolumn{9}{|l|}{ iex } \\
\hline Iale & -0.75 & 0.126 & $\begin{array}{l}0.57(0.44- \\
0.72) \\
\end{array}$ & $<0.001 *$ & -0.40 & 0.215 & $\begin{array}{l}0.67(0.44- \\
1.02) \\
\end{array}$ & 0.061 \\
\hline emale* & - & - & - & - & - & - & - & - \\
\hline \multicolumn{9}{|l|}{ ocial status } \\
\hline ingle & 0.23 & 0.126 & $\begin{array}{l}1.25(0.98- \\
1.61) \\
\end{array}$ & 0.073 & -0.12 & 0.229 & $\begin{array}{l}1.13(0.72- \\
1.77) \\
\end{array}$ & 0.605 \\
\hline 1 relationship* & - & - & - & - & - & - & - & - \\
\hline \multicolumn{9}{|l|}{ Oonthly income } \\
\hline 2000 & 0.05 & 0.151 & $\begin{array}{l}1.05(0.78- \\
1.41)\end{array}$ & 0.749 & 0.21 & 0.256 & $\begin{array}{l}1.23(0.74- \\
2.03)\end{array}$ & 0.421 \\
\hline $000-5000$ & 0.01 & 0.121 & $\begin{array}{l}1.01(0.80- \\
1.28) \\
\end{array}$ & 0.929 & -0.23 & 0.224 & $\begin{array}{l}0.80(0.51- \\
1.23) \\
\end{array}$ & 0.307 \\
\hline $5000 *$ & - & - & - & - & - & - & - & - \\
\hline \multicolumn{9}{|l|}{ Iigh risk group in home } \\
\hline Гo & -0.33 & 0.097 & $\begin{array}{l}0.72(0.60- \\
0.87) \\
\end{array}$ & $0.001 *$ & -0.48 & 0.178 & $\begin{array}{l}0.62(0.44- \\
0.88)\end{array}$ & $0.007^{*}$ \\
\hline es* & - & - & - & - & - & - & - & - \\
\hline \multicolumn{9}{|l|}{ ype of quarantine } \\
\hline Iy work requires that I stay outdoors & 0.02 & 0.145 & $\begin{array}{l}1.02(0.77- \\
1.35) \\
\end{array}$ & 0.905 & 0.48 & 0.224 & $\begin{array}{l}1.62(1.04- \\
2.51) \\
\end{array}$ & $0.033^{*}$ \\
\hline am obliged to stay at home* & - & - & - & - & - & - & - & - \\
\hline \multicolumn{9}{|l|}{ ny of relatives or acquainted infected? } \\
\hline Гo & -0.57 & 0.260 & $\begin{array}{l}0.57(0.34- \\
0.94) \\
\end{array}$ & $0.029 *$ & -0.89 & 0.399 & $\begin{array}{l}0.41(0.19- \\
0.90)\end{array}$ & $0.026 *$ \\
\hline es* & - & - & - & - & - & - & - & - \\
\hline \multicolumn{9}{|l|}{ fraid of getting COVID-19 or transmit it? } \\
\hline Го & -0.61 & 0.130 & $\begin{array}{l}0.55(0.42- \\
0.70) \\
\end{array}$ & $<0.001 *$ & -0.31 & 0.219 & $\begin{array}{l}0.73(0.48- \\
1.13) \\
\end{array}$ & 0.155 \\
\hline es* & - & - & - & - & - & - & - & - \\
\hline \multicolumn{9}{|l|}{ 'roperly informed about quarantine } \\
\hline Го & 0.30 & 0.120 & $\begin{array}{l}1.35(1.06- \\
1.71) \\
\end{array}$ & $0.013^{*}$ & 0.20 & 0.214 & $\begin{array}{l}1.22(0.80- \\
1.85)\end{array}$ & 0.361 \\
\hline es* & - & - & - & - & - & - & - & - \\
\hline \multicolumn{9}{|l|}{ iource of information } \\
\hline elevision or radio & -0.38 & 0.263 & $\begin{array}{l}0.68(0.41- \\
1.14) \\
\end{array}$ & 0.148 & 0.12 & 0.459 & $\begin{array}{l}1.13(0.46- \\
2.77) \\
\end{array}$ & 0.795 \\
\hline Ifficial government agencies & -0.43 & 0.274 & $\begin{array}{l}0.65(0.38- \\
1.11) \\
\end{array}$ & 0.117 & -0.41 & 0.503 & $\begin{array}{l}0.66(0.25- \\
1.78) \\
\end{array}$ & 0.414 \\
\hline health care worker & -0.93 & 0.336 & $\begin{array}{l}0.39(0.20- \\
0.76) \\
\end{array}$ & $0.006^{*}$ & 0.22 & 0.505 & $\begin{array}{l}1.25(0.47- \\
3.36) \\
\end{array}$ & 0.659 \\
\hline ocial media & -0.47 & 0.243 & $\begin{array}{l}0.63(0.39- \\
1.01) \\
\end{array}$ & 0.054 & 0.35 & 0.430 & $\begin{array}{l}0.71(0.30- \\
1.64)\end{array}$ & 0.416 \\
\hline onversation with other people* & - & - & - & - & - & - & - & - \\
\hline \multicolumn{9}{|c|}{ nough food supply to withstand quarantine period? } \\
\hline Гo & 0.42 & 0.109 & $\begin{array}{l}1.52(1.23- \\
1.88) \\
\end{array}$ & $<0.001 *$ & 0.63 & 0.191 & $\begin{array}{l}1.88(1.30- \\
2.74) \\
\end{array}$ & $0.001 *$ \\
\hline es* & - & - & - & - & - & - & - & - \\
\hline \multicolumn{9}{|l|}{ ommitment inside home precautions } \\
\hline ow level & -0.03 & 0.099 & $\begin{array}{l}0.97(0.80- \\
1.18) \\
\end{array}$ & 0.761 & 0.00 & 0.180 & $\begin{array}{l}1.00(0.70- \\
1.42)\end{array}$ & 0.998 \\
\hline [igh level* & - & - & - & - & - & - & - & - \\
\hline $\begin{array}{lll}\begin{array}{l}\text { ielf-rating } \\
\text { sontinuous) }\end{array} & \text { quarantine } & \text { commitment } \\
\end{array}$ & 0.12 & 0.030 & $\begin{array}{l}1.01(0.96- \\
1.07)\end{array}$ & 0.680 & -0.07 & 0.047 & $\begin{array}{l}0.94(0.86- \\
1.03)\end{array}$ & 0.159 \\
\hline
\end{tabular}

Page 12/15 
「ote: likelihood Ratio Test of the final model fitting significance was $<0.001$. Pearson chi-square test for model goodness-of-fit was ignificance 0.30 .

\begin{tabular}{|c|c|c|c|c|c|c|c|c|}
\hline \multirow[b]{2}{*}{ Tariable } & \multicolumn{4}{|c|}{ Mild to moderate } & \multicolumn{4}{|c|}{ Severe to extremely severe } \\
\hline & B & SE & OR (95\%CI) & $P$-value & B & $\mathrm{SE}$ & OR (95\%CI) & $P$-value \\
\hline ige (continuous) & -0.04 & 0.006 & $0.97(0.95-0.98)$ & $<0.001 *$ & -0.05 & 0.008 & $0.96(0.94-0.97)$ & $<0.001^{*}$ \\
\hline \multicolumn{9}{|l|}{ ex } \\
\hline Iale & -0.44 & 0.116 & $0.64(0.51-0.81)$ & $<0.001 *$ & -0.93 & 0.143 & $0.40(0.30-0.52)$ & $<0.001 *$ \\
\hline emale* & - & - & - & - & & - & - & - \\
\hline \multicolumn{9}{|l|}{ iocial status } \\
\hline ingle & -0.11 & 0.125 & $0.90(0.70-1.15)$ & 0.394 & -0.02 & 0.142 & $0.98(0.74-1.30)$ & 0.901 \\
\hline 1 relationship* & - & - & - & - & - & - & - & - \\
\hline \multicolumn{9}{|l|}{ jeographic area } \\
\hline$\overline{\text { Jest Bank }}$ & -0.29 & 0.185 & $0.75(0.52-1.08)$ & 0.121 & 0.00 & 0.222 & $1.00(0.65-1.55)$ & 0.999 \\
\hline iaza & -0.57 & 0.245 & $0.56(0.35-0.91)$ & $0.019 *$ & 0.09 & 0.271 & $1.09(0.64-1.86)$ & 0.749 \\
\hline эrusalem* & - & - & - & - & - & - & - & - \\
\hline \multicolumn{9}{|l|}{ ducational level } \\
\hline econdary or less & 0.08 & 0.223 & $1.09(0.70-1.68)$ & 0.711 & -0.22 & 0.256 & $0.80(0.49-1.32)$ & 0.387 \\
\hline ollage & 0.10 & 0.180 & $1.11(0.78-1.57)$ & 0.578 & -0.13 & 0.201 & $0.88(0.59-1.31)$ & 0.527 \\
\hline Iaster or decorate* & - & - & - & - & - & - & - & - \\
\hline \multicolumn{9}{|l|}{ Tonthly income } \\
\hline 2000 & 0.34 & 0.157 & $1.41(1.03-1.91)$ & $0.030 *$ & 0.07 & 0.170 & $1.08(0.77-1.50)$ & 0.661 \\
\hline$\overline{000-5000}$ & 0.18 & 0.123 & $1.19(0.94-1.52)$ & 0.156 & -0.16 & 0.136 & $0.86(0.66-1.12)$ & 0.254 \\
\hline $5000 *$ & - & - & - & - & - & - & - & - \\
\hline \multicolumn{9}{|l|}{ Iigh risk group in home } \\
\hline Го & -0.14 & 0.097 & $0.87(0.72-1.06)$ & 0.164 & -0.41 & 0.109 & $0.67(0.54-0.82)$ & $<0.001 *$ \\
\hline es* & - & - & - & - & - & - & - & - \\
\hline \multicolumn{9}{|c|}{ fraid of getting COVID-19 or transmit it? } \\
\hline Io & -0.53 & 0.124 & $0.59(0.46-0.75)$ & $<0.001 *$ & -0.26 & 0.133 & $0.77(0.60-1.01)$ & 0.055 \\
\hline es* & - & - & - & - & - & - & - & - \\
\hline \multicolumn{9}{|c|}{ roperly informed about quarantine } \\
\hline Io & 0.21 & 0.121 & $1.24(0.98-1.57)$ & 0.079 & 0.33 & 0.133 & $1.39(1.07-1.80)$ & $0.014^{*}$ \\
\hline es* & - & - & - & - & - & - & - & - \\
\hline \multicolumn{9}{|l|}{ ource of information } \\
\hline elevision or radio & -0.59 & 0.275 & $0.56(0.32-0.95)$ & $0.033 *$ & -0.66 & 0.295 & $0.52(0.29-0.92)$ & $0.025^{*}$ \\
\hline Ifficial government agencies & -0.76 & 0.286 & $0.51(0.29-0.90)$ & $0.020 *$ & -0.44 & 0.301 & $0.64(0.36-1.16)$ & 0.141 \\
\hline health care worker & -0.66 & 0.326 & $0.52(0.27-0.98)$ & $0.042^{*}$ & -0.62 & 0.344 & $0.54(0.28-1.06)$ & 0.074 \\
\hline ocial media & -0.39 & 0.255 & $0.68(0.41-1.12)$ & 0.131 & -0.52 & 0.270 & $0.59(0.35-1.01)$ & 0.052 \\
\hline onversation with other people* & - & - & - & - & - & - & - & - \\
\hline \multicolumn{9}{|c|}{ nough food supply to withstand quarantine period? } \\
\hline Io & 0.40 & 0.110 & $1.49(1.20-1.85)$ & $<0.001 *$ & 0.67 & 0.122 & $1.96(1.54-2.49)$ & $<0.001^{*}$ \\
\hline es* & - & - & - & - & - & - & - & - \\
\hline
\end{tabular}

\section{Figures}




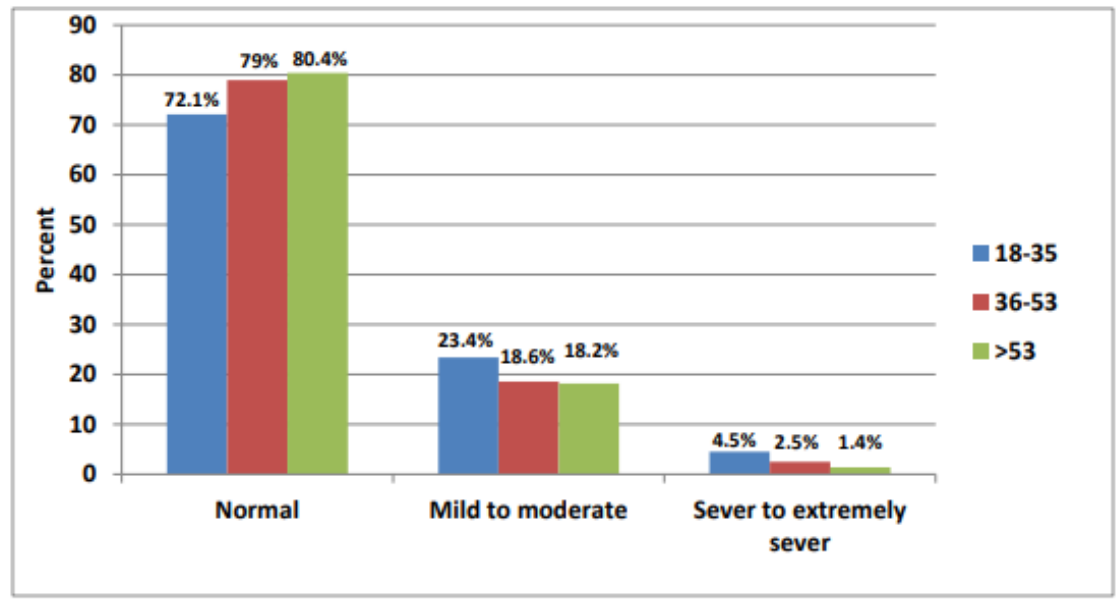

Figure 1

\section{Figure 1}

Age distribution among anxiety severity ( $P$-value $<0.001 ; \mathrm{N}=2819)$.

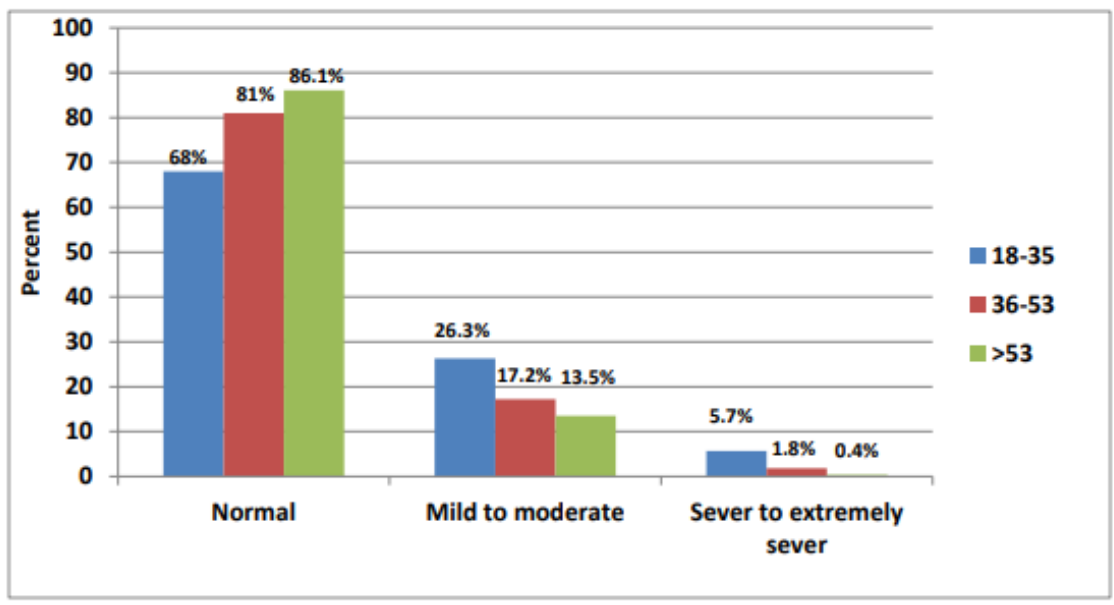

Figure 2

\section{Figure 2}

Age distribution among stress severity ( $P$-value $<0.001 ; \mathrm{N}=2819$ ).

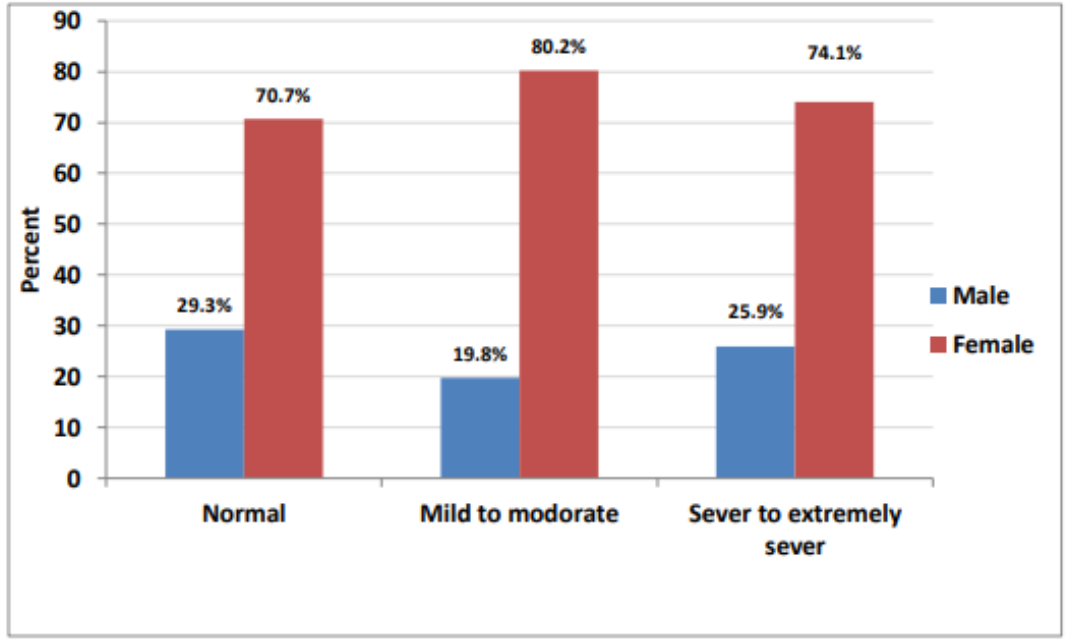

Figure 3

Figure 3 
Sex distribution among anxiety severity ( $\mathrm{P}$-value $<0.001 ; \mathrm{N}=2819)$.

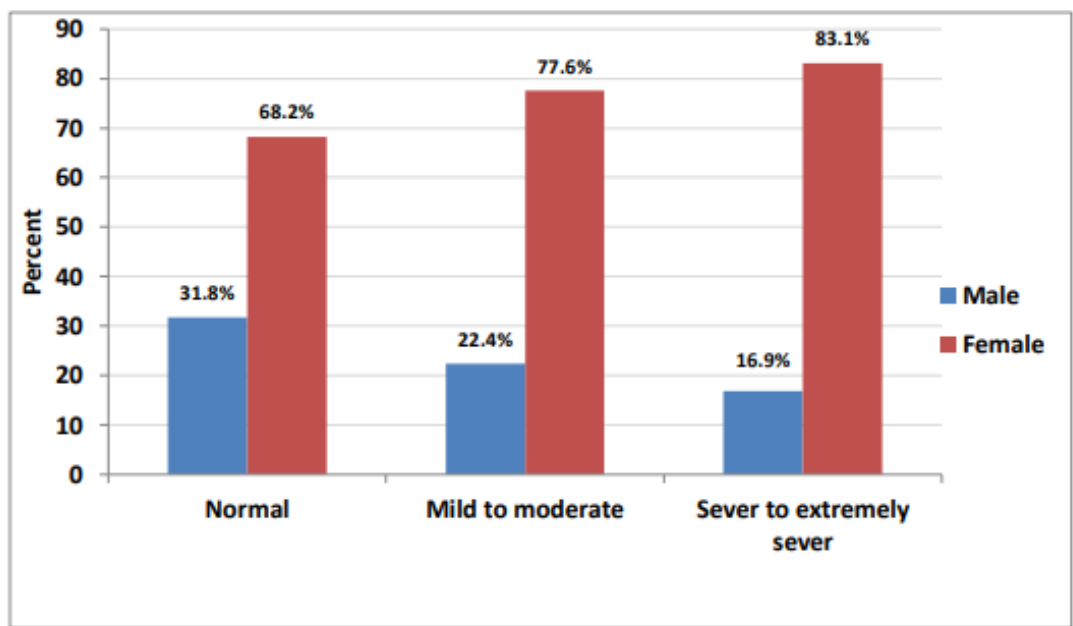

Figure 4

\section{Figure 4}

Sex distribution among stress severity ( $P$-value $<0.001 ; N=2819$ ). 